\title{
João do Rio: uma alma encantada pelas ruas do Rio de Janeiro
}

Vera Casa Nova I UFMG

\begin{abstract}
Resumo: O artigo trata do encantamento de João do Rio pelas ruas do Rio de Janeiro, filiando esse autor a outros que como ele mostram ruas e cidades dentro de um regime de imagens caracterizando uma visibilidade típica da contemplação literária.

Palavras-chave: narrativa e regime de imagens, a rua e seu encanto na visibilidade literária.
\end{abstract}

\begin{abstract}
A representação realista nas narrativas do final do século XIX e no início do século XX, aponta para o regime de imagens como, por exemplo, o da rua, na relação entre sujeito e objeto. Para dar uma mostra de um certo tipo de visibilidade na literatura brasileira, selecionei um texto - o da conferência de João do Rio, publicado na Gazeta de Notícias do Rio de Janeiro, em 29 de outubro de 1905 - intitulado "A Rua".

$\mathrm{O}$ amor da rua e a louvação à rua comum no início do século XX (1905), em João do Rio mostra-se caracterizado pelo corpo daquele que vê a ruamulher, a rua-mãe, a rua-vida/morte. A partir daí signos a serem lidos pelo autor/ narrador, que, no mesmo movimento, instaura a travessia física, ou seja, o que se passa através dos olhos e as matérias observadas ligadas à vida e aos destinos do homem e dele próprio podem ser encontrados na narrativa.
\end{abstract}


O que está diante do narrador-sujeito-aquele que seleciona a partir dos objetos que o olham, impondo um dentro e um fora, a rua-o objeto, como um corpo feminino - ora materno, ora prostituído -, instaura um "inelutável modo de sua visibilidade".

Ver e tocar, duas experiências que envolvem o visível e o tangível nesse encantamento, ou seja, "como se o ato de ver acabasse sempre pela experimentação tátil de um obstáculo erguido diante de nós, obstáculo talvez perfurado, feito de vazios", ' caracterizam certas narrativas dessa fase literária, por mais que sua representação passe pelo viés da representação mimética.

Nesse percurso das ruas, o narrador vai-se constituindo, enquanto pensa na transformação e na variação de afetos e sentimentos do mundo. Tocado pela rua, por esse sentimento que envolve a todos os artistas que viveram nessa época, vendo as transformações, João do Rio diz:

Eu amo a rua. Esse sentimento de natureza toda interna não vos seria revelado por mim se não julgasse, e razões não tivesse para julgar, que este amor assim absoluto e assim exagerado é partilhado por todos vós. Nós somos irmãos, nós nos sentimos parecidos e iguais; nas cidades, nas aldeias, nos povoados, não porque soframos, com a dor e os desprazeres, a lei e a polícia, mas porque nos une, nivela e agremia o amor da rua. É este mesmo o sentimento imperturbável e indissolúvel, o início que, como a própria vida, resiste às idades e às épocas. ${ }^{2}$

A rua, abstração e concretude que não escapa da "inelutável modalidade do visível", assim é vista/descrita no texto de João do Rio, em algumas de suas passagens:

1. "A rua! Que é a rua? Um cançonetista de Montmartre fá-la dizer: 'je suis la rue, femme éternellement verte, je n'ai jamais trouvé d'autre carrière ouverte'."

2. "A rua é um fator da vida das cidades, a rua tem alma!"

3. "A rua é agasalhadora da miséria".

4. "A rua é generosa".

5. "A rua é transformadora das línguas".

6. "A rua nasce, como o homem, do soluço do espasmo."

1. DIDI-HUBERMAN, 1998, p. 31.

2. RIO, 1997, p. 45. 
7. "A rua sente nos nervos essa miséria da criação, e por isso, é a mais igualitária, a mais socialista, a mais niveladora das obras humanas."

8. "A rua é a eterna imagem da ingenuidade. Comete crime, desvaria à noite, treme com febre dos delírios, para ela como para as crianças a aurora é sempre formosa..."

9. "A rua faz as celebridades e as revoltas, a rua criou um tipo universal."

10. "Para compreender a psicologia da rua não basta gozar-lhe as delícias como se goza o calor do sol e o lirismo do luar. É preciso ter espírito vagabundo, cheio de curiosidades malsãs e os nervos com um perpétuo desejo incompreensível, é preciso ser aquele que chamamos flâneur e praticar o mais interessante dos esportes - a arte de flanar."

Segundo Raul Antelo, no estudo que introduz a obra, "ler é uma forma de ser" ${ }^{3}$ - assim é que o espetáculo do mundo está na rua em cores e ritmos que espelham a alma, o ritmo inquietante da rua e do olhar do narrador. João do Rio lê a rua. A cada verbo "ser" que acompanha a descrição da rua, toda a sociedade, seus humores e mortes acontecidas ou pressentidas - "uma superfície que só é plana para dissimular e ao mesmo tempo indicar a profundeza que a habita, que a move..." ${ }^{4}$ - se dão a ver.

Superfície e profundidade emergem na rua. Esse texto exemplificaria como fez Didi-Huberman com Joyce, essa "inelutável modalidade do visível”, pois oferece, em suas descrições da rua os componentes teóricos que fazem de um plano ótico, do que o narrador vê, uma potência visual que o olha, pois põe em ação o jogo anadiômeno (o termo é de Vênus anadiômena, que significa "saídas da água"), jogo rítmico, que coloca a rua e o ler/olhar sobre ela em fluxo e refluxo no movimento de seus passantes e habitantes do Rio.

Esse mesmo jogo se instaura no flâneur parisiense que Walter Benjamin iria estudar e que tantos críticos brasileiros relacionam a esse texto de João do Rio.

"Que significa flanar?" com essa pergunta o narrador discorre sobre a experiência daqueles dias: misto de observação, admiração e vadiagem, João do Rio nos descreve a "arte de flanar - perambular com inteligência" por entre a

3. RIO, 1997, p. 15 .

4. DIDI-HUBERMAN, 1998, p. 33. 
multidão e as ruas da cidade. Aí se estabelece a relação flâneur/alma das ruas apontando para o animismo especular - flâneur $/$ rua:

11. "Cada rua é para mim um ser vivo e imóvel".

12. "São assim as ruas de todas as cidades, com vida e destinos iguais aos do homem."

13. "Algumas dão para malandragens, outras para austeras; umas são pretensiosas, outras riem aos transeuntes e o destino as conduz como conduz o homem."

"Oh! Sim, as ruas têm alma!" Frase síntese da conferência nessa exortação ao sentimento dedicado às ruas: Rua do Ouvidor, Rua da Misericórdia, Rua da Quitanda, Rua das Laranjeiras, ruas de Santa Tereza, Rua de Haddock Lobo, Senhor dos Passos, Rua do Senado, Largo do Machadinho têm alma, sobretudo em "horas tardias". "Se as ruas são seres vivos, as ruas pensam, têm idéias, filosofia e religião...".

Expandem-se assim rua/sociedade, rua/intelecto, rua/cultura.

Nas grandes cidades a rua passa a criar o seu tipo, a plasmar o moral dos seus habitantes, a inocular-lhes misteriosamente gostos, costumes, hábitos, modos, opiniões políticas. Vós todos deveis ter ouvido ou dito aquela frase: "- Como essas meninas cheiram a Cidade Nova".

Ou ainda, a "rua faz o indivíduo"... E "no espírito humano a rua chega a ser uma imagem que se liga a todos os sentimentos e serve para todas as comparações."

O texto pode ser considerado, por sua temática, um texto-sintoma. Didi-Huberman observa como o sintoma se caracteriza ao mesmo tempo por sua intensidade visual, seu valor de brilho e sua dissimulação do fantasma inconsciente que está no texto: "O sintoma é uma entidade semiótica de dupla face: entre o brilho e a dissimulação, entre o acidente e o incontrolável, entre o acontecimento e a estrutura."

5. RIO, 1997, p. 53

6. RIO, 1997, p. 55

7. RIO, 1997, p. 62

8. RIO, 1997, p. 76 .

9. DIDI-HUBERMAN, 1990, p. 308. 
Sintoma, aqui, não é doença ou motivo consciente, ou desejo recalcado sob um texto, é um trabalho da figurabilidade, pois se supõe que haja uma figuração, da mesma forma que todo enunciado poético supõe enunciação.

Esse conceito está no limite de dois campos teóricos: o da ordem fenomenológica e o da ordem semiológica, pois esse limite se marca pelo afeto, pela existência de um narrador.

À noite, a visibilidade da rua é mais acessível, por mais contraditório que seja isso. A paisagem da rua chama, faz um apelo, aos artistas da época e às categorias estéticas não só da tradição como também da contemporaneidade.

Todos os sinais de mudança da rua também os são dos homens. O visível e o identificável ainda podiam ser dimensionados. Posteriormente as referências e os limites seriam abalados.

A rua em João do Rio guarda ainda essa visibilidade. Objetos, signos sócio-culturais da atividade humana ainda estão ali, mesmo que o narrador comece já a ver, ou melhor, a reconhecer mudanças.

No jogo diurno e noturno da rua, do aparecimento e do desaparecimento, a rua se revela como "volume" do lugar.

O próprio ato de flanar em João do Rio está ligado ao regime de imagens que obedece aos fluxos de significação, mostrando o caráter subjetivo despertado pelo objeto. Todos os signos da rua produzem e criam sentidos pode-se dizer que se trata mesmo da descoberta do sentido como presença (e não como ausência), e o jogo no ato de descrever faz o aparecimento e o desaparecimento das ruas, de lugares e sítios criando sentidos, ou seja, dando alma, segundo o autor, aos signos visíveis.

O paradigma noturno é uma das tônicas da obra de João do Rio - a inquietação que instaura na ordem do visível a espacialidade do lugar e do sentimento.

As imagens mostradas no texto pela palavra do conferencista-narrador seguem as categorias de seu saber, de seu pensar. Entre o ver e esse saber deslizam metáforas, abrem-se camadas do simbólico e do imaginário, entre a representação e a apresentação, entre símbolos e sintomas. Enfim, entre a noção habitual do visível e uma noção renovada do visual.

Aproximar-se é contar, recontar, mostrar um trecho:

É o sentido fundamental que se diz aqui, é o teor etimológico da palavra - o corte - e sua primeira definição no Littré: divisão de uma coisa em 
várias partes, em pedaços, o que abre toda a constelação semântica do lado da troca e do proveito, do comércio de detalhes... ${ }^{10}$

O recorte, o corte e o pedaço da rua como significante. Enumerar as partes de um todo, descrevendo detalhes articulando-os, pedaços do visível que às vezes se ocultam, mas, se descobertos, se exibem e se deixam identificar, como verdadeiros objetos semióticos que se desdobram através de comentários, como esse a seguir: "Na literatura atual a rua é a inspiração dos grandes artistas, desde Victor Hugo, Balzac e Dickens, até às epopéias de Zola [...]. Não há um escritor moderno que não tenha cantado a rua."

Ou ainda: "Mas a quem não fará sonhar a rua? A sua influência é fatal na palheta dos pintores, na alma dos poetas, no cérebro das multidões. Quem criou o reclamo? A rua! Quem inventou a caricatura? A rua!". ${ }^{12}$

Sintoma do tempo. Ao mostrar a rua, como objeto semiótico, João do Rio chama a atenção de sua época para a passagem da modernidade. Assim como W. Benjamin fez com a moda, João do Rio faz da descrição da rua uma predição das mudanças históricas.

A rua fica, literalmente, na fronteira entre os séculos, onde o sujeito vê seu tempo, sua história. O posicionamento do conferencista dá conta de sua significância emblemática. Sobre a influência da rua na vida do fim de século, João do Rio mostra como a renovação urbana reorganiza os dados simbolizando a mudança. No deslocamento dessa mudança da natureza das ruas, a força vital da sexualidade aí presente no texto, também se desloca. "Balzac dizia que as ruas de Paris não são impressões humanas. São assim as ruas de todas as cidades, com vida e destinos iguais aos dos homens." ${ }^{13}$

$\mathrm{Na}$ representação da rua como essência do universal, a figura do flâneur examina detalhes e compara o corpo do homem ao corpo da rua, aí incluindo-se sentimentos de toda ordem, pois "oh! Sim, as ruas têm alma" " e assim faz desfilar toda a fantasmagoria desse espaço. E é essa alma que João do Rio consegue trazer a seu texto, sob o signo da visibilidade.

10. DIDI-HUBERMAN, 1990, p. 274.

11. RIO, 1997, p. 78.

12. RIO, 1997, p. 79

13. RIO, 1997, p. 55

14. RIO, 1997, p. 55 
Em outro texto, "A pintura das ruas", o narrador chama a atenção para os "pintores anônimos, os pintores da rua, os heróis da tabuleta, os artistas da arte prática". 15 Ou ainda em "Tabuletas", "Visões d'ópio", "Cordões", "As mariposas do luxo", o regime de imagens está presente para reafirmar "a poesia da encantadora alma das ruas" ${ }^{16}$ do Rio de Janeiro do início do século XX - campo, fundo, formato do mundo imaginal de João do Rio em suas articulações fundamentais.

Como no trabalho das Passagens de Walter Benjamin, o material de João do Rio está cheio de evidências das transformações que se dão a ver a todo instante nas ruas da cidade cosmopolita. Como em Baudelaire, mostrando que a função da arte é construir imagens da cidade, João do Rio faz-nos redescobrir as paisagens da cidade mergulhando-nos nelas, para que as vejamos e elas nos olhem, instaurando assim o inelutável modo de sua visibilidade, ou seja, faz da rua uma forma que nos olha.

Resumé: Cet essai montre l'enchantement de João do Rio par les rues de Rio de Janeiro, que se rejoint à d'autres auteurs qui comme lui montrent les rues et les villes dans le régime des images caracterisant une visibilité typique de la contemplation littéraire.

Mots-clés: récit et régime des images, la rue et sa séduction dans la visibilité littéraire.

\section{Referências Bibliográficas}

DIDI-HUBERMAN, Georges. Devant l'image. Paris: Minuit, 1990.

DIDI-HUBERMAN, Georges. O que vemos e o que nos olha. São Paulo: Ed. 34, 1998.

RIO, João do. A alma encantadora das ruas. Organização de Raul Antelo. São Paulo: Companhia das Letras, 1997.

15. RIO, 1997, p. 147

16. RIO, 1997, p. 405. 